\title{
SÍNDROME DE BOURNOUT EM PROFESSORES DO ENSINO MÉDIO: UM ESTUDO QUALITATIVO BASEADO NO MODELO BIOGRÁFICO DE KELCHTERMANS
}

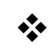 \\ Luciane Marques Raupp \\ Centro Universitário La Salle - Unilasalle - Canoas - Brasil \\ Douglas Eliesler Justen \\ Centro Universitário La Salle - Unilasalle - Canoas - Brasil
}

\section{Resumo}

A flexibilização e a precarização do trabalho na pós-modernidade contribuem para que, no exercício profissional da atividade docente, encontrem-se diversos estressores psicossociais, alguns relacionados à natureza de suas funções, outros relacionados ao contexto institucional e social onde estas são exercidas. Assim, muitos profissionais são submetidos a fatores que podem provocar a Síndrome de Burnout. Ao estudar o Burnout, grande número de pesquisas tem se utilizado de métodos quantitativos, que definem previamente seus objetivos de avaliação. Como uma alternativa a esta tendência, o presente trabalho se utilizou do campo qualitativo, pautando sua pesquisa no modelo Biográfico de Kelchtermans, para analisar preditores da Síndrome de Burnout em 11 professores do Ensino Médio de dois colégios da rede particular de ensino de Porto Alegre/RS. Os resultados obtidos apontam para a presença de significativos níveis de Exaustão Emocional e Baixa Realização Profissional, duas das três subescalas que caracterizam a Síndrome de Burnout.

Palavras-chave: Professores, Síndrome de Burnout, Psicologia.

\section{Introdução}

O trabalho no mundo contemporâneo ocupa um papel central e fundamental na construção das identidades dos sujeitos e, parafraseando Sartre (2002), em seus projetos de vida. Conforme Aquino, et al. (2012, p. 103), o trabalho é tão antigo quanto o próprio ser humano, tendo surgido antes mesmo do nascimento do processo civilizatório. É a partir dele que o homem modifica seu meio e é modificado por ele. Ao longo da história da humanidade o processo laboral sofreu diversas transformações, tanto em seu sentido e importância quanto na forma de se trabalhar. Com o avanço das necessidades humanas, novas demandas começaram a surgir e o trabalho ganhou complexidades, evoluindo de seu objetivo inicial que era contribuir para a sobrevivência da espécie. As condições às quais o trabalho é desenvolvido, assim como a relação que o sujeito estabelece com ele, ocasionam 
consequências à subjetividade do ser humano, gerando implicações diversas. E estas decorrências são, muitas vezes, de caráter imaterial.

Bauman (2000) afirma que na "modernidade pesada", exemplificada pelo modelo de produção fordista, os horizontes de tempo para o trabalhador eram de longo prazo. Havia uma relação em geral vitalícia entre empregado e empregador, onde o primeiro, uma vez inserido em algum emprego, poderia estar certo de que terminaria sua vida de trabalho no mesmo lugar. Porém, na atualidade esta situação mudou. A nova mentalidade do curto prazo veio a substituir a de longo prazo. Na "modernidade líquida", flexibilidade é a palavra da moda e, quando aplicada ao mercado de trabalho, resulta em contratos precários ou de curto prazo, cargos sem estabilidade, incertezas e um crescente processo de individuação do trabalhador (Bauman, 2000, p. 168).

Diante deste novo cenário, a incerteza é uma força individualizante. Neste contexto, o trabalhador está enfraquecido, dividido, e sem interesses em comum com outros na mesma condição. "Em geral isso significa uma população dócil, sem desejar e sem ser capaz de oferecer uma resistência organizada a quaisquer decisões que o capital possa tomar" (Bauman, 2001, p. 39). Se no passado os empregados podiam exercer seu poder coletivo e forçar os empresários a negociarem acordos que melhorassem seu modo de vida, hoje, em função da individualização e, por conseguinte, da fragmentação da sociedade moderna, as coisas se modificaram. Atualmente há uma busca constante pela otimização da 'pessoatrabalhador', cujo qual tem de ser imune a falhas, numa busca desenfreada pela perfeição. Dentro deste ideal, a competição é o fio condutor e, caso não se atinja os níveis desejados, a mensagem é simples: todos são substituíveis (Bauman, 2001).

Dejours (1992) aponta que a individualização do trabalho fragilizou as possibilidades de defesas coletivas dos trabalhadores. $\mathrm{O}$ fracionamento da coletividade apagou as iniciativas espontâneas de lutas por melhores condições, e a individualização conduziu à particularização do sofrimento de um trabalhador em relação a outro. Isto, por sua vez, fez com que as respostas em relação à atividade laboral fossem cada vez mais personalizadas (p. 40).

Segundo Tittoni (2009, p. 168), a contemporaneidade é pautada pela flexibilização das regulamentações e das relações de trabalho, gerando um novo perfil de trabalhador: "flexível, comprometido, colaborador e polivalente”. Esta flexibilização tem consequências na produção de subjetividade, exigindo que o capital desenvolva um trabalhador sempre bem preparado para o mercado e suas novidades, dotado de um constante medo ameaçador de estar sem trabalho e construindo uma existência na qual a atividade laboral é o elemento central. " $\mathrm{Na}$ 
relação entre subjetividade e trabalho, as pessoas consomem o seu trabalho e são consumidas por ele" (Tittoni, et al. 2009, p. 169).

A intensificação do trabalho, ocasionada pelo aumento do ritmo das jornadas, das responsabilidades e da complexidade das tarefas, vem produzindo tensões que afetam sobremaneira a relação saúde-doença, colocando o estresse como uma das principais causas de adoecimento laboral. Esse desequilíbrio na saúde do trabalhador pode ocasionar o aparecimento de diversos outros sintomas psíquicos como a Síndrome da Fadiga Crônica, a depressão, a Síndrome de Burnout, e demais distúrbios inespecíficos, ainda pouco conhecidos. Em relação às consequências fisiológicas, aumentam os índices de adoecimento e de morte por doenças cardiovasculares e doenças crônico-degenerativas, como as osteomusculares (Andrade \& Cardoso, 2012).

Normalmente a patologia não é muito aceita no meio laboral. Isto ocorre principalmente porque nesse ambiente os valores construídos estão muito relacionados à produtividade. Assim, acredita-se que a doença pode comprometer os resultados e as metas da empresa (França, 1999 apud Andrade \& Cardoso, 2012, p. 131).

O trabalho, a doença e o sofrimento são causas de desgaste físico e psicológico, frequentemente resultando no desenvolvimento do estresse ocupacional por parte do profissional. Uma das categorias que é acometida pelo estresse ocupacional e, principalmente, pela Síndrome de Burnout, é a dos professores. Segundo Carlotto (2011), a profissão docente é classificada pela Organização Internacional do Trabalho (OIT) dentre as mais estressantes.

A organização do trabalho do professor, atualmente, possui características que o expõem a fatores estressantes que, se persistentes, podem ocasionar a Síndrome de Burnout. No caso de sua ocorrência, leva os professores a um processo de alienação, apatia, problemas de saúde e à intenção de abandonar a profissão.

Preocupado com essas questões, este estudo procurou identificar se professores da rede particular de ensino da cidade de Porto Alegre apresentam características sintomatológicas de Burnout ou a predisposição a desenvolvê-lo. Porém, mais do que diagnosticar, fez-se necessário também investigar fatores capazes de fornecer subsídios para prevenir e tratar o Burnout. É consenso, no meio da saúde, que um ambiente de trabalho saudável e seguro configura um dos principais fatores que inibem o aparecimento da Síndrome. 


\section{Síndrome de Bournout em professores}

Podemos definir a Síndrome de Burnout como um estresse que ocasiona exaustão emocional, despersonalização e baixa realização pessoal no trabalho. A exaustão emocional tem como característica a falta de energia e uma sensação de esgotamento emocional. A despersonalização ocorre quando o profissional desenvolve sentimentos e atitudes negativas, pautadas pela impessoalidade para com os indivíduos destinatários de seu trabalho. Já a baixa realização profissional caracteriza-se pela autoavaliação negativa, despertando sentimentos de incompetência em relação à profissão (Carlotto \& Câmara, 2008, p. 30).

O Burnout tem sido considerado um problema social de extrema relevância, pois se encontra vinculado a custos organizacionais, devido à rotatividade de pessoal, absenteísmo, problemas de produtividade e qualidade e também por associar-se a vários tipos de disfunções pessoais como o surgimento de graves problemas psicológicos e físicos (Benevides-Pereira, 2010).

A síndrome foi primeiramente identificada na década de 1970 pelo psiquiatra Freudenberger. Ele percebeu que muitos profissionais da área médica, ao longo de suas carreiras, desenvolviam quadros de insensibilidade e desinteresse por sua atividade laboral, a qual antes era motivo de paixão pelos mesmos. Também percebeu que muitos deles desenvolviam sintomas físicos em decorrência do estresse ocasionado pelo ofício. Através de um método baseado na observação clínica, definiu o Burnout como um estado de esgotamento físico e mental, cuja causa está intimamente ligada com a atividade profissional das pessoas (Dutra-Thomé, et al., 2014, p. 108-109).

Estudos realizados no Brasil demonstram que o Burnout é a doença ocupacional que ocorre com mais frequência entre os professores. Isso se dá em função de vários aspectos, como a baixa valorização, o nível de envolvimento e responsabilidade com os alunos, a sobrecarga da jornada de trabalho, a remuneração insuficiente, excesso de demandas burocráticas, clima organizacional, entre outras características, particulares de cada realidade (Andrade \& Cardoso, 2012, p. 134). Ao se analisar a prevalência da Síndrome de Burnout (SB) em professores, percebemos que se deve levar em consideração não somente o caráter de seu cargo, mas a disposição e organização do trabalho pelas instituições e como os professores percebem o tratamento dado por elas (Carlotto \& Câmara, 2008, p. 39).

De acordo com Lipp (2012), a Síndrome de Burnout atinge pessoas que trabalham principalmente em profissões de ajuda, onde os contatos interpessoais são muito intensos, como no caso dos professores. Muitas vezes, esta síndrome pode ser gerada por expectativas 
profissionais elevadas e não realizadas e, o excesso de engajamento, se não reconhecido, pode gerar um sentimento de frustração e exaustão no profissional, que pode se estender para todas as áreas de sua vida. Professores mais realistas nas suas expectativas com relação ao trabalho tendem a desenvolver um maior equilíbrio em suas vidas (p. 64-66).

\section{Bournout e o modelo biográfico de Kelchtermans}

Para o estudo e diagnóstico da Síndrome de Burnout em educadores muitas pesquisas tem sido realizadas, em sua maioria utilizando testagens quantitativas, sendo o Maslach Burnout Inventory (MBI) a principal escala psicológica utilizada para o diagnóstico clínico. No entanto, publicações recentes apontam para a necessidade de se analisar aspectos integrais e subjetivos da profissão docente, os quais não podem ser compreendidos quantitativamente (Dutra-Thomé, et al., 2014).

Como opção de ferramenta de pesquisa qualitativa surge o método Narrativo Biográfico de Kelchtermans. Neste, os participantes são estimulados a refletir sobre suas carreiras e relatar os significados das experiências vividas. O modelo de Kelchtermans possui três focos de orientação: o primeiro busca analisar a trajetória profissional, onde os entrevistados relatam os cargos e funções ocupados em sua história profissional; o segundo analisa sua identidade profissional, buscando refletir sobre como o profissional percebe suas competências, seus interesses laborais e como está o seu desempenho em todos os contextos de seu trabalho; o terceiro ponto tem seu foco na vivência atual do exercício profissional, onde os indivíduos descrevem como está sua situação atual de trabalho, trazendo para a reflexão tanto aspectos ambientais quanto subjetivos (Dutra-Thomé, et al., 2014 p. 112).

Kelchtermans, através de seu método biográfico, propõe investigar o desenvolvimento profissional dos professores de forma integral, relacionando aspectos de sua história com elementos da vivência atual. Esta é uma perspectiva que parte do pressuposto de que as experiências vividas ao longo da carreira geram reflexos e significados no comportamento profissional dos docentes. Pode-se dizer que o método de Kelchtermans aproxima-se da experiência singular e particular do indivíduo, fornecendo uma visão de Burnout enquanto processo, analisando variáveis tanto laborais quanto culturais (Dutra-Thomé, et al., 2014 p. 16). 


\section{Método}

Os participantes deste estudo foram onze professores que exercem atividade docente no Ensino Médio em duas escolas privadas localizadas na cidade de Porto Alegre/RS. As escolas possuem uma média de 1.200 alunos, atingindo os três níveis de ensino: educação infantil, ensino fundamental e ensino médio, e se equivalem no que diz respeito ao número de professores. Os professores participantes do estudo são em sua maioria mulheres $(72,7 \%)$. Possuem tempo de experiência docente de, em média, 14,5 anos e trabalham em média 32 horas/aula por semana.

Para avaliar a Síndrome de Burnout foi elaborado um roteiro com 16 questões descritivas sob a forma de um questionário autoaplicável baseado no modelo de Kelchtermans (1999). O modelo proposto por Kelchtermans, através de seus três focos orientadores (Trajetória Profissional, Identidade Profissional, Vivência atual do exercício profissional), é adequado para investigar Burnout principalmente por fornecer dados subjetivos da vida laboral, propiciando a investigação de detalhes da predisposição ou desenvolvimento da Síndrome na trajetória individual, e acesso a experiência pessoal de cada um (Dutra-Thomé, et al., 2014 p. 112). As questões elaboradas abrangiam uma ampla possibilidade de respostas e possibilitavam ao individuo refletir sobre si mesmo de forma integral.

Para a coleta de dados primeiramente foi realizado um contato com a direção das instituições de ensino, momento no qual foram apresentados os objetivos do estudo com o intuito de obter a autorização para a aplicação da pesquisa. Após, foi realizado o convite aos professores e, aos que se dispuseram a participar, foi entregue o questionário, bem como combinado a data para sua devolução: aproximadamente vinte dias após o recebimento dos mesmos pelos educadores. A pesquisa foi aprovada pelo Comitê de Ética do Unilasalle/Canoas conforme parecer $n^{\circ} 821.292$.

Para análise das respostas do questionário foi utilizado o método de Análise de Conteúdo (Bardin, 1977), o qual consiste em um conjunto de instrumentos metodológicos aplicados aos discursos, através dos quais possibilita a análise das comunicações, decompondo-as e elencando categorias. Durante este procedimento, foram identificados temas a partir do questionário realizado, os quais delinearam a constituição de categorias e suas subsequentes interpretações. 


\section{Resultados}

A análise do conteúdo das respostas se deu partir dos três focos propostos pelo modelo de Kelchtermans: vivência atual do exercício profissional, identidade profissional e trajetória profissional. Procurou-se analisar e dar maior ênfase aos elementos que apareceram de maneira uniforme na maioria das respostas aos questionários.

Os resultados obtidos mostram que os professores compartilham de um sentimento de vulnerabilidade em seu trabalho, principalmente no que se refere à falta de estabilidade no emprego, baixa valorização profissional e pouco apoio das instituições. A qualidade de vida é sentida como baixa em consequência da alta carga horária de trabalho, do excesso de tarefas realizadas fora do ambiente escolar e das doenças crônicas desenvolvidas em decorrência da atividade laboral. Na relação com os alunos os educadores se mostram motivados com as possibilidades de aprendizado e de contribuir na formação de novas gerações. No entanto a falta de comprometimento e de respeito por parte dos alunos foi apontada como fator desmotivador.

Percebe-se um alto grau de exigência dos educadores com seu próprio trabalho, ocasionando uma busca constante pela competência. Ter o trabalho reconhecido pelos alunos e pela instituição apareceu como um elemento importante. O desejo de ensinar, socializar o conhecimento e de contribuir com a sociedade mostraram-se aspectos motivadores na escolha da docência como profissão. Porém, atualmente, $81 \%$ dos professores já pensaram e/ou pensam em mudar de atividade. Há, a partir da análise das respostas, uma predisposição ao desenvolvimento da Síndrome de Burnout entre os professores pesquisados.

\section{Discussão dos resultados}

Foi objetivo desse estudo analisar as relações entre Burnout, características individuais, estressores laborais e história de vida profissional dos professores.

Como aspecto importante, um dos pontos do questionário buscou entender a motivação da escolha pela docência. De acordo com Cherniss (1995 apud Dutra-Thomé, 2014, p. 111), os profissionais, no início de suas carreiras, possuem um conjunto de ideais e propósitos futuros, carregados de um enorme desejo de contribuírem através de sua prática profissional para melhorarem as condições de vida da sociedade. Isso decorre do fato de os profissionais estarem conectados a objetivos mais amplos do que a atividade do trabalho em si. C Caso 
estes ideais fracassem, há uma grande possibilidade de frustração e desmotivação e, como consequência, de sofrimento psíquico.

Através da pesquisa da Trajetória Profissional dos participantes, identificaram-se fortes ideais ligados à escolha da profissão, que podem ser percebidos em discursos como: "Resolvi ser professor por sempre ter ideais de uma sociedade melhor"; "Tornei-me professora, pois achava fascinante o fato de transmitir aquilo que gosto, pelo contato com os alunos e por acompanhar o crescimento intelectual deles"; ou ainda "Eu queria ser significativo de alguma forma".

Na dimensão Identidade Profissional, a pesquisa demonstrou que os professores se sentem cada vez mais desafiados em seu trabalho, principalmente no que se refere ao emprego de metodologias que atendam aos novos perfis dos alunos, gerando níveis de insegurança e ansiedade. Uma variável interessante foi a forma como os educadores acreditam que são vistos pelos alunos: de forma positiva. Expressões como "confiável, competente, organizado, dedicado e dinâmico" apareceram diversas vezes, direta ou indiretamente. Ao se avaliarem no autoconceito "pontos fortes", os discursos mostraram-se muito parecidos com a maneira pela qual creem que são percebidos pelos alunos. Demonstram, em decorrência disto, uma boa capacidade de autoestima, aspecto este importante para estratégias de coping. Conforme, Mendes, et al (2012), autoimagem e autoestima positiva, através das quais o educador percebe e reconhece sua importância como agente transformador de seus alunos, contribuem para que se estabeleçam relações mais saudáveis no ambiente de trabalho, "otimizando a ação pedagógica e qualificando o processo de ensino e de aprendizagem” (p. 12).

Ao analisar a vivência atual do exercício profissional, o comportamento dos alunos e a indisciplina apareceram como fatores estressores. Um ambiente de sala de aula com estas características desenvolve relações pedagógicas pautadas pela resistência e improdutividade. Conforme pesquisa realizada em 2008 na escola básica Egas Moniz, em Guimarães, no norte de Portugal, há divergências entre o que os educadores e os alunos consideram como atos de indisciplina. Trocar empurrões ao entrar na escola, utilizar o celular em sala de aula, chegar atrasado para o período, não foram considerados comportamentos indisciplinares pela maioria dos alunos (Gomes, et al, 2010, p. 99). Esta dissociação de compreensões gera dificuldades para se construir combinações disciplinares, desenvolvendo um ambiente patológico e diminuindo a sensação de realização com o trabalho desenvolvido.

Carlotto (2010) aponta que professores do Ensino Médio estão mais predispostos a desenvolver Burnout, apresentando um maior índice de despersonalização. Isso se dá principalmente pelo perfil dos alunos, em sua maioria adolescentes, tendo o professor que 
lidar, além dos estressores típicos da docência, com as características dessa etapa do desenvolvimento. Neste sentido professores do Ensino Médio tendem a apresentar menor satisfação profissional do que em relação aos outros níveis escolares (p. 500).

Esse fator pode ser percebido em várias respostas dos professores pesquisados, como nos exemplos a seguir: "Hoje estar em sala de aula é um estresse. Tem que prever o que pode acontecer em todos os momentos, principalmente situações desagradáveis. Você tem que se preocupar mais com o comportamento do que com o conhecimento"; "os alunos estão ultimamente sem limites"; "o estresse se dá principalmente com relação à imposição de limites e com relação à postura de sala de aula (falta de respeito)”.

O sentimento de insegurança diante da possibilidade de demissão contribui para o aparecimento da exaustão emocional (Dalagasperina \& Monteiro, 2014, p. 271). Nos professores pesquisados, esta variável apareceu em muitos relatos. A instabilidade mostra-se uma particularidade do ensino privado. O medo de perder o emprego desperta ansiedades, principalmente quando se aproxima o término do ano letivo (Donatelli \& Oliveira, 2010, p. $50-51)$.

A alta carga horária de trabalho e o excesso de tarefas realizadas fora do ambiente laboral são fatores que influenciam a qualidade de vida dos docentes. Segundo Lipp (2012, p.60), o contexto atual interligou de maneira uniforme e singular o mundo pessoal e o mundo profissional. Mesmo fisicamente fora do trabalho, as tarefas não se esgotam e, cada vez menos, os professores conseguem dividir a vida particular da vida laboral, tendo o trabalho invadido sobremaneira sua privacidade. Conforme Gomes \& Quintão (2011, p. 336)., o Burnout é uma resposta à sobrecarga e a quantidade de tarefas realizadas, bem como ao nível de pressão exigido, os quais estão ligados à dimensão da exaustão emocional.

$\mathrm{Na}$ pesquisa realizada esses aspectos também foram classificados pelos professores como elementos estressores do trabalho: "Trabalho muito, pois minha demanda é muito grande. Levo muito trabalho para casa e por isso não consigo aproveitar meu tempo livre”. "Tem dias da semana que dou 11 aulas, algumas turmas com mais de 40 alunos, tendo que organizar muitas atividades burocráticas inclusive. Eu me sinto muito cansada e ao chegar em casa, ainda tenho que trabalhar". "Como cheguei a trabalhar em três escolas diferentes, uma em outra cidade, acabei surtando. Fiquei muito cansado e sem conseguir relaxar e dormir. (...) Minha vida era só trabalho. Amava minha profissão, mas neste momento ela passou a me sugar, destruiu minhas forças".

No trabalho do professor, é comum o desenvolvimento de outras doenças, físicas ou mentais, que afetam a qualidade de vida e são ocasionadas pela prática laboral. Ao serem 
questionados se já desenvolveram problemas de saúde em relação à profissão, $63 \%$ dos professores afirmaram que sim: "Desenvolvi tendinite e síndrome do túnel do carpo, ambas devido ao uso excessivo da escrita e do computador, para a realização de trabalhos, cronogramas e planejamentos, aulas e todo o material que preciso desenvolver, por ter muito conteúdo e não usar livro na escola"; "Hérnia de disco (segundo meu médico, o tipo de hérnia que desenvolvi é comum em professor ou dentista, no meu caso a prática de escrever no quadro e sobrecarregar mais um lado foi crucial)"; "Desde infecção urinária, problemas musculares, estresse e depressão"; "Labirintite causada pelo estresse”; "Insônia em função da incomodações (...), pressão alta em função do stress”.

Conforme Webber \& Vergani (2010), o magistério sempre foi considerado uma profissão desgastante, inclusive pela legislação, que através do Decreto 53.831/64 classificou a função docente como penosa. Os fatores ergonômicos, tanto fisiológicos como psicológicos, podem produzir alterações no organismo e no estado emocional, comprometendo a saúde do trabalhador. Conforme a OIT, o contato com o público é um fator de risco para o desenvolvimento de doenças psicossomáticas. Além disto, as lesões por esforços repetitivos e distúrbios osteomusculares estão interligados com as novas demandas da sala de aula, bem como do mundo atual, pautado pela constante aceleração no que se refere à produção.

$\mathrm{Na}$ atualidade, os professores se sentem desvalorizados em sua profissão. A baixa valorização é um aspecto importante para o desenvolvimento do Burnout (Farber, 1999). Conforme Lipp, "ocorreu uma deterioração das condições da formação e da prática profissional do professorado no Brasil, hoje tão desvalorizado no próprio universo acadêmico, na mídia e na sociedade em geral” (2012, p. 15).

Este sentimento de desvalorização é carregado pelos professores e influencia diretamente em sua autoestima, elemento chave para a construção de estratégias de enfrentamento da realidade profissional. Segundo os relatos dos professores: “(...) percebemos que as famílias têm mais persuasão sobre a escola do que nós, professores. Nossa autonomia profissional se perde a cada dia e isso nos entristece e nos desestimula”. "Gosto do que faço, mas não vejo possibilidades de mudança de um contexto que não acredita no conhecimento. É muito frustrante. (...) A cobrança dos pais e da escola é constante ao professor, mas ninguém quer parar para ver qual é o verdadeiro papel de cada um nesse processo”. "A falta de valorização, o desrespeito e a baixa remuneração, são as principais dificuldades".

A pesquisa demonstrou que a maioria dos professores já pensou em mudar de profissão, principalmente em função da baixa valorização profissional. "Se fosse jovem hoje, realmente 
abandonaria tudo, não creio que haverá mudança e estamos ficando doentes com toda esta carga. Não é justo”; "Sim. Minha qualidade de vida não está como deveria. Trabalho muito e não consigo aproveitar os frutos deste trabalho. Sem falar do estresse. Parece que estou sempre andando numa corda bamba”; "Vou mudar. Por que não aguento mais!”; “(...) Pensei nisso, pois acredito que o professor não recebe o devido valor que merece. Temos uma carga de trabalho exagerada que muitas vezes não é reconhecida”.

Neste contexto, Carlotto afirma que em professores com Burnout há um forte desejo de abandonar a profissão, atitude esta que é tomada principalmente por docentes jovens e a motivação de abandonar o trabalho se configura numa forma de tentar lidar com a exaustão emocional. Altos níveis de Burnout fazem os educadores 'contarem a horas' para o dia de trabalho terminar (2002, p. 27). A frustração, a decepção e o senso de fracasso profissional contribuem para que o profissional não veja sentido em seu trabalho (Silva, 2006, p. 94).

A partir da análise dos resultados obtidos através das respostas dos participantes, percebemos que a organização atual do trabalho destes professores possui diversos fatores estressantes que podem contribuir para o desenvolvimento da Síndrome de Burnout. Esses fatores são avaliados pelos professores a partir de sua personalidade, experiências passadas e estilo de vida. Caso a interpretação das vivências ocorra de forma negativa e se o educador não possuir estratégias de enfrentamento adequadas, podem-se desenvolver sintomas característicos do Burnout (Lipp, 2012, p. 71).

Pesquisar a Síndrome de Burnout a partir do Modelo de Kelchtermans permitiu uma visão integral da profissão docente. A partir das respostas obtidas percebe-se que os itens de diagnóstico de Burnout: Exaustão Emocional e Baixa Realização Profissional aparecem de maneira objetiva na autoavaliação realizada pelos professores. A partir da metodologia qualitativa empregada, cada professor pôde expressar sua forma particular de vivenciar a profissão docente, respondendo questões e revivendo aspectos de sua trajetória profissional, de sua identidade profissional, bem com da vivência atual de seu exercício profissional. Neste sentido, o Burnout tem de ser compreendido enquanto processo, permitindo ao indivíduo refletir sobre sua própria singularidade (Kelchtermans, 1999).

Ao analisar a profissão docente e seus diversos fatores de saúde e doença, é necessário compreender que esta atividade laboral esta inserida em um cenário mais amplo, refletindo as características e dinâmicas dos processos de trabalho na atualidade. Bauman (2001), ao caracterizar a Modernidade Líquida, aponta para questões como a individualização dos comportamentos, o imediatismo, a insegurança e a precariedade do trabalho. Estes elementos transformaram a maneira de o trabalhador vivenciar sua atividade produtiva gerando novas 
subjetividades. Neste contexto, a flexibilização do trabalho ganha cada vez mais importância, fazendo com que a base central da existência dos sujeitos seja a atividade laboral (Tittoni et al., 2009).

\section{Considerações finais}

Este estudo buscou analisar o papel do trabalho e os aspectos relacionados à profissão docente na sociedade contemporânea, como as patologias que decorrem desta atividade laboral, especificamente a Síndrome de Burnout. Foi constatado que a flexibilização e a precarização do trabalho afetam os profissionais de maneira negativa, influenciando sua vida laboral e pessoal.

Nos professores pesquisados, identificou-se preditores para o desenvolvimento do Burnout, conclusão esta que pode ser obtida nas respostas dos participantes, onde aparecem objetivamente duas das três subescalas que compõem o diagnóstico da Síndrome segundo Maslach: Exaustão Emocional e Baixa Realização Pessoal no Trabalho. O método qualitativo de Kelchtermans proporcionou o aparecimento de fatores subjetivos da personalidade dos docentes. Pode-se dizer que os estressores desta profissão estão relacionados com a forma como o trabalho é organizado, que apresenta fatores de risco para o desencadeamento da Síndrome (Dalagasperina \& Monteiro, 2014, p. 272).

Faz-se necessário, após conhecer os preditores do Burnout, elaborar medidas e programas de prevenção para que o professor aprenda a lidar com o estresse de modo eficaz. Uma das estratégias utilizadas pode ser a de coping, que são estratégias pessoais, pautadas por esforços cognitivos e comportamentais, que cada indivíduo utiliza para reagir ao estresse. " $E$ ' também um fenômeno adaptativo que possibilita a adequação do indivíduo ao desempenho das suas atividades em diversas vertentes da vida” (Pocinho \& Perestrelo, 2011, p. 522).

Estratégias de coping focadas na resolução de problemas permitem que o profissional atue sobre a situação, controlando o nível de estresse e melhorando seu bem estar físico e psicológico, além de aumentar seu sentimento de realização profissional (Pocinho \& Perestrelo, 2011, p. 523-524).

Nesse sentido, caberia às instituições de ensino o desenvolvimento de estratégias de qualidade de vida no trabalho para os professores. Cursos de formação e workshops abordando técnicas de enfrentamento do estresse e do Burnout tornam-se extremamente relevantes para o professor organizar sua vida pessoal e profissional de uma maneira saudável, adotando mecanismos de prevenção. 
'É importante também que as escolas ajudem a fortalecer o papel do professor dentro e fora do ambiente educacional, reconhecendo seu trabalho, abrindo espaços de diálogo e de apoio em relação aos problemas, diminuindo o excesso de tarefas burocráticas muitas vezes desnecessárias e oferecendo melhores oportunidades de realização profissional. Em relação aos professores, é fundamental que estes busquem sentido em seu trabalho, que desenvolvam atitudes positivas, organizem melhor seu tempo e suas prioridades, aprendam técnicas de manejo do estresse e aumentem sua autoeficácia (Lipp, 2012, p. 77-79).

Cada vez mais se mostra necessário a utilização de diferentes e múltiplas metodologias a fim de poder-se analisar a Síndrome de Burnout sob óticas diversas, tendo em vista a multiplicidade de fatores que a englobam. Encontrar respostas sobre como o trabalho impacta a vida dos professores e pesquisar elementos de prevenção e promoção da saúde devem ser objetivos de futuros estudos nesta área, visto a necessidade urgente de um maior cuidado com a profissão docente.

\title{
BOURNOUT SYNDROME IN SECONDARY SCHOOL TEACHERS: A QUALITATIVE STUDY BASED ON KELCHTERMAN'S MODEL
}

\begin{abstract}
The flexibility and precariousness of work in post modernity, focusing in the practice of teaching activity, contribute to, that several psycho social stressors might happen. Some, related to the nature of their duties or tasks; others, associated to the institutional and social context, in which they are practiced. Therefore, so many professionals are subject of factors that may cause the Burnout Syndrome. By studying the Syndrome of Burnout, a large amount of research has used quantitative methods, which previously define its evaluation goals. An alternative to that trend is brought by this Academic Study that uses the qualitative field, basing its researches in the Kelchtermans' biography model to analyze prognosticators of Burnout Syndrome in eleven (11) High School teachers of two private school in the city of Porto Alegre, State of Rio Grande do Sul. The results obtained indicate the presence of significant levels of Emotional Exhaustion and Low Professional Achievement. Two out of three sub scales that represent the Burnout Syndrome
\end{abstract}

Key words: Teachers, Burnout Syndrome, Work.

\section{REFERÊNCIAS}

AGUIAR, R.; ALMEIDA, S. Mal Estar na Educação: o sofrimento psíquico de professores. Curitiba: Juruá, 2008. 
AQUINO, Cássio et al. Flexibilização e Intensificação Laboral: Manifestações da Precarização do Trabalho e suas Consequências para o Trabalhador. Labor. Fortaleza, v. 1, no 7, p. 102-125, 2012. Disponível em:

<http://www.revistalabor.ufc.br/Artigo/volume7/7_Flexibilizacao_e_intensificacao_laboral__manifestacoes_da_precarizacao_do_trabalho_e_suas_consequencias_para_o_trabalhador_Ca ssio_Adriano_Braz_de_Aquino.pdf>.Acesso em 04 nov. 2014.

AQUINO, Cássio. Reflexões sobre a Precarização Laboral: uma perspectiva da psicologia social. II Jornada Internacional de Políticas Públicas. São Luís, ago. 2005. Disponível em: <http://www.joinpp.ufma.br/jornadas/joinppIII/html/Trabalhos2/Cassio_adriano_b._Aquino2 19.pdf>. Acesso em: 12 ago. 2014.

ANDRADE, P.; CARDOSO, T. Prazer e Dor na Docência: revisão bibliográfica sobre a Síndrome de Burnout. Saúde Soc. São Paulo, v.21, n.1, p.129-140, Jan/Mar 2012. Disponível em: 〈http://www.scielo.br/pdf/sausoc/v21n1/13.pdf>. Acesso em: 12 ago. 2014.

BARDIN, Laurence. Análise de conteúdo. Lisboa: Edições 70, 1977.

BAUMAN, Zygmunt. A Sociedade Individualizada: vidas contadas e histórias vividas. Rio de Janeiro: Zahar, 2001.

BAUMAN, Zygmunt. Modernidade Líquida. Rio de Janeiro: Zahar, 2000.

BENEVIDES-PEREIRA, A. M. T. Burnout: quando o trabalho ameaça o bem-estar do trabalhador. 3. ed. São Paulo: Casa do Psicólogo, 2010.

BITTENCOURT, Fátima. Estresse: o mal do século. Psique: Ciência \& Vida, São Paulo, v. 6, n. 63, p.24-31, mar. 2011. Disponível em:

<http://psiquecienciaevida.uol.com.br/ESPS/Edicoes/63/artigo211972-1.asp>. Acesso em: 12 ago. 2014.

CARLOTTO, Mary Sandra. Síndrome de Burnout em professores de instituições particulares de ensino. Aletheia, $\mathrm{n}^{\circ}$ 17-18, Jan/dez 2003. Disponível em:

<http://www.redalyc.org/pdf/1150/115013455006.pdf>. Acesso em: 24 set. 2013.

. Síndrome de Burnout: diferenças segundo níveis de ensino. Psico. Porto

Alegre, v. 41, n. 4, p. 495-502, out/dez 2010. Disponível em:

<http://revistaseletronicas.pucrs.br/fo/ojs/index.php/revistapsico/article/view/4881/5958>.

Acesso em: 20 set. 2014.

Síndrome de Burnout em Professores: Prevalência e Fatores Associados.

Psicologia: Teoria e Pesquisa. Brasília, vol. 27, n.4, p. 403-410, Out/Dez 2011. Disponível em: <http://www.scielo.br/scielo.php?script=sci_arttext\&pid=S0102-37722011000400003>. Acesso em: 15 out. 2014.

CARLOTTO, M. S.; PALAZZO, L. S. Síndrome de Burnout e fatores associados: um estudo epidemiológico com professores. Cadernos de Saúde Pública, Rio de Janeiro , v. 22, n. 5 , p.1017-1026, maio 2006. Disponível em: 〈http://www.scielo.br/pdf/csp/v22n5/14.pdf〉. Acesso em: 24 set. 2014. 
CARLOTTO, M. S.; CÂMARA, S. Síndrome de Burnout e estratégias de enfrentamento em professores de escolas públicas e privadas. Psicologia da Educação. São Paulo, 26, $1^{\circ}$ sem. de 2008, p. 29-46. Disponível em: <http://pepsic.bvsalud.org/pdf/psie/n26/v26a03.pdf>. Acesso em: 24 set. 2014.

CELSO, Maria Cristina. Síndrome de Burnout e formação de professores/as: fatores de adoecimento e estratégias de enfrentamento dos docentes. Dissertação (Mestrado), UEPA, Centro de Ciências Sociais, Mestrado em Educação, 2012.

CODO, Wanderley. Burnout: sofrimento psíquico dos trabalhadores em educação. São Paulo: Kingraf, 2000.

COTRIM, P. S.; WAGNER, L. C. Prevalência da Síndrome de Burnout em professores de uma Instituição de Ensino Superior. Ciência em Movimento, Porto Alegre, v.13, n.28, p. 6170, jul. 2012. Disponível em: https://www.metodista.br/revistas/revistasipa/index.php/EDH/article/view/142>. Acesso em: 24 set. 2014.

DA SILVA, Maria Emília. Burnout: por que sofrem os professores? Estudos e Pesquisas em Psicologia, Rio de Janeiro, ano 6, n. 1 p. 89-98, 2006. Disponível em:

<http://www.revispsi.uerj.br/v6n1/artigos/PDF/v6n1a08.pdf>. Acesso em: 15 out. 2014.

DALAGASPERINA, P.; MONTEIRO, J. Preditores da Síndrome de Burnout em Docentes do Ensino Privado. Psico-USF, Itatiba, v.19, n.2, p. 265-275, maio/agosto 2014. Disponível em: <http://www.scielo.br/pdf/pusf/v19n2/a09v19n2.pdf>. Acesso em: 01 nov. 2014.

DEJOURS, Christophe. A Loucura do Trabalho: Estudo de Psicopatologia do Trabalho. São Paulo: Cortez, 1992.

DELBROUCK, Michel. Síndrome da Exaustão: Burnout. Coleção Manuais Universitários. Vol. 47. Portugal: Climepsi Editores, 2006.

DONATELLI, S.; OLIVEIRA, J. O trabalho de professores da educação básica do Rio Grande do Sul. Porto Alegre: Fundacentro, 2010.

DUTRA-THOMÉ, L., ALENCASTRO, L. S., \& KOLLER, S. H. A narrativa como proposta metodológica para o estudo do Burnout. Psicologia e Sociedade, Porto Alegre, 2014, p. 107116. Disponível em:

<http://www.ufrgs.br/seerpsicsoc/ojs2/index.php/seerpsicsoc/article/view/3729/2356>. Acesso em 07 set. 2014.

FARBER, B. A. Inconsequentiality - The key to understanding teacher burnout. Em Vanderbergue, R. \& Huberman, M. A. (Eds.), Understanding and preventing teacher burnout: a source book of international practice and research. Cambridge: Cambridge University Press, 1999, p. 159-165).

FERENHOF, I. A.; FERENHOF, E. A. Burnout em professores. Eccos - Revista Científica Avaliação e Mudanças - Centro Universitário Nove de Julho, v. 4, n. 1, p. 131-151. 2002. 
Disponível em:

$<$ http://tupi.fisica.ufmg.br/ michel/docs/Artigos_e_textos/Stress_qualidade_de_vida/007\%20 B\%20-\%20Burnout\%20em\%20professores\%20-\%20ARTIGO.pdf $>$. Acesso em: 24 set. 2013.

GOMES, A. P.; QUINTÃO, S. Burnout, Satisfação com a Vida, Depressão e Carga Horária em Professores. Análise Psicológica. Lisboa, vol. 29, n. 2, p. 335-344, Abr. 2011. Disponível em: < http://www.scielo.oces.mctes.pt/scielo.php?pid=S0870-

$82312011000200010 \&$ script=sci_arttext\&tlng=pt $>$. Acesso em: 01 nov. 2014.

GOMES, Carlos et al. A indisciplina numa escola portuguesa: olhares da comunidade educativa. Educação em Revista, Marília, v.11, n.1, p.93-104, Jan/Jun 2010. Disponível em: <http://www2.marilia.unesp.br/revistas/index.php/educacaoemrevista/article/viewFile/660/54 3> Acesso em: 02 nov 2014.

GOMIDE, Paula Inez Cunha et al. Correlação entre práticas educativas, depressão, estresse e habilidades sociais. Psico-USF, Bragança Paulista, v.10, n. 2, p. 169-178, jul. 2005.

Disponível em: <http://pepsic.bvsalud.org/pdf/psicousf/v10n2/v10n2a08.pdf>. Acesso em: 31 out. 2014.

Kelchtermans, G. Teaching career: Between Burnout and fading away? Reflections from a narrative and biographical perspective. In R. E. Vanderbergue \& M. A. Huberman (Eds.), Understanding and preventing teacher Burnout: A source book of international practice and research (p. 176-191). Cambridge: Cambridge University Press, 1999.

LEVY, G.; SOBRINHO, F. (orgS.). A Síndrome de Burnout em professores do Ensino Regular: pesquisas, reflexões e enfrentamento. Rio de Janeiro: Cognitiva, 2011.

LEVY, Gisele et al. Síndrome de Burnout em Professores da Rede Pública. Produção, São Paulo, v. 19, n.3, p. 458-465, set/dez 2009. Disponível em:

<http://www.scielo.br/scielo.php?pid=S0103-65132009000300004\&script=sci_arttext >. Acesso em: 01 nov. 2014.

LIPP, Marilda Novaes. O Stress do Professor. 7. ed. Campinas, SP: Papirus, 2002.

MASLACH, C. et al. Job Burnout. Annual Review Psychology, vol. 52, p. 397-422, 2001. Disponível em: <http://www.annualreviews.org/doi/abs/10.1146/annurev.psych.52.1.397>. Acesso em 20 set. 2014.

MENDES, Aline et al. Autoimagem, Autoestima e Autoconceito: Contribuições Pessoais e Profissionais na Docência. Anais IX Anpedsul, 2012. Disponível em:

<http://www.ucs.br/etc/conferencias/index.php/anpedsul/9anpedsul/paper/viewFile/724/374> Acesso em: 31 out. 2014.

POCINHO, M.; PERESTRELO, C. Um Ensaio sobre Burnout, Engagement e Estratégias de Coping na Profissão Docente. Educação e Pesquisa, São Paulo, v.37, n.3, p.513-528, set/dez 
2011. Disponível em: <http://www.scielo.br/scielo.php?pid=S1517-

$97022011000300005 \&$ script=sci_arttext $>$. Acesso em 01 nov. 2014.

PORTO, Israel Costa et al. Doenças Ocupacionais em Professores Atendidos pelo Centro de Estudos da Saúde do Trabalhador. Revista Baiana de Saúde Pública, v. 28, n.1 p.33-49 jan/jun 2004. Disponível em: <http://bases.bireme.br/cgibin/wxislind.exe/iah/online/?IsisScript=iah/iah.xis\&nextAction $=$ lnk\&base $=$ LILACS\&exprSearch=404574\&indexSearch=ID\&lang=p $>$. Acesso em: 24 set. 2014.

SARTRE, Jean-Paul. O Ser e o Nada. 13 ed. Petrópolis, RJ: Vozes, 2005.

TITTONI, Jaqueline et al. O Trabalho no Contexto da Acumulação Flexível e a Produção de Subjetividade. Psicologia em Revista. Belo Horizonte, v.15, n.2, p. 166-183, ago. 2009.

Disponível em: <

http://periodicos.pucminas.br/index.php/psicologiaemrevista/article/view/P.1678-

9563.2009v15n2p166>. Acesso em: 11 ago. 2014.

UNESCO. O Docente como Protagonista na Mudança Educacional: Bem estar Revista Prelac, v. 1, n. 1, p. 116-133, jun. 2005. Disponível em:

<http://unesdoc.unesco.org/images/0014/001446/144666por.pdf>. Acesso em: 04 ago. 2014.

WEBER, D.; VERGANI, V. A profissão de professor na sociedade de risco e a urgência por descanso, dinheiro e respeito no meio ambiente laboral. Anais do XIX Encontro Nacional do CONPED, Fortaleza, p. 8807-8823, jun. 2010. Disponível em: <http://www.sinprocaxias.com.br/igc/uploadAr/FileProcessingScripts/PHP/UploadedFiles/a_ profissao_de_professor.pdf>. Acesso em: 02 nov. 2014.

Data de recebimento: $31 / 03 / 16$

Data de aceite: $23 / 03 / 17$

\section{Sobre os autores:}

Luciane Marques Raupp é Psicóloga, Doutora em Saúde Pública. Professora e pesquisadora do Mestrado de Memória Social e Bens Culturais do Unilasalle-Canoas. Endereço Eletrônico: luciane.raupp@unilasalle.edu.br

Douglas Eliesler Justen é Bacharel em Psicologia e Teologia pelo Centro Universitário La Salle. Atua como Professor na Rede Privada de Ensino e como Psicólogo Clínico. Endereço Eletrônico: douglasjusten@yahoo.com 